\title{
Study of selected physical, chemical and biological properties of selected materials intended for contact with human body
}

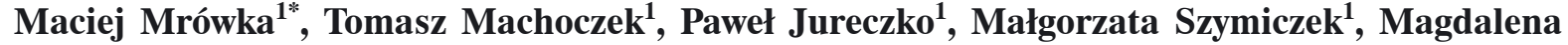 \\ Skonieczna $^{2}$, Łukasz Marcoll ${ }^{3}$ \\ ${ }^{1}$ Silesian University of Technology, Institute of Theoretical and Applied Mechanics, Faculty of Mechanical Engineering, \\ 18A Konarskiego Str., 44-100 Gliwice, Poland \\ ${ }^{2}$ Silesian University of Technology, Institute of Automatic Control, Faculty of Automatic Control, Electronics and Computer \\ Science, Akademicka 16 Str., 44-100 Gliwice, Poland \\ ${ }^{3}$ Marcoll Sp. z o. o., Kotuchy 20 St., 41-946 Piekary Ślaskie, Poland \\ *Corresponding author: e-mail: maciej.mrowka@polsl.pl
}

\begin{abstract}
The purpose of the conducted study was to analyse new materials intended for contact with the human body in view of their physical, chemical and biological properties. The authors have put to test six commercially available materials, four out of which were composite polyamide 12-based materials, while two were polyurethanes. The examined materials were assessed in terms of the surface. Subsequently, their hardness and biocompatibility were tested. The authors devoted major attention to the tests of absorption and emissivity of water, the $\mathrm{pH}=7.4 \mathrm{PBS}$ buffer solution and $\mathrm{pH}=4.3$ artificial sweat in temperatures of $21^{\circ} \mathrm{C}$ and $37^{\circ} \mathrm{C}$. The results of the tests have confirmed the non-toxicity of all the tested materials and allowed to provide their characteristics in terms of their surface, hardness, as well as absorption and emissivity of various body fluids. Both polyamide 12 and the tested polyurethanes are classified as thermoplastics that may be used in additive technology.
\end{abstract}

Keywords: absorption, hardness, biocompatibility, structural materials, emissivity.

\section{INTRODUCTION}

Due to the dynamic development of additive manufacturing methods that allow to achieve shapes that were not previously achievable using traditional methods, there is a clear need to perform physical and chemical tests. The difficulties that arise in the mechanical tests of the materials processed using these methods force scientists to make major efforts in terms of planning the complexity of the experiments pertaining to numerous variables ${ }^{1,8}$. The complexity of the experiment plans is a result of a wide range of technological parameters and variable ambient conditions, which drive the researchers to seek innovative and - unfortunately - often highly complicated solutions. A way of coping with this is the so-called monoselectivity of the conducted experiments. It results from the fact that the components produced using additive technology based on 3D printing are characterized by different properties depending on the set production parameters: e.g. the temperature of the printer's table, input material processing temperature, the thickness and width of the applied layer, work, the content level and type of the filler and the ambient air humidity. Professional literature includes an increasingly wide range of results concerning various mechanical studies conducted using samples produced with these methods ${ }^{5,6,7}$. However the available materials used in the additive technologies as well as their quantitative and qualitative composition are, often proprietary. It causes problems related to the identification of their physical and chemical properties ${ }^{4}$. Due to mentioned reasons, this publication presents the analysis of selected structural materials that are beneficial in view of their density and non-toxicity ${ }^{8}$. The selection was based on the application of these materials, requiring the materials to be appropriate for direct contact with human skin. The authors limited the planned tests to ones significant from the point of view of constructors-technologists, namely the hardness, absorptivity and biocompatibility tests as well as the tests of the surface structure ${ }^{4,9,11}$.

\section{MATERIAL AND METHODS}

\section{Material}

Six samples produced from commercially available materials were subjected to analysis. Four of them were polyamide 12-based composite materials (samples P1, P2, P3 and P4), produced by Evonik and two were polyurethane foams (samples P5 and P6) under the trade names of iT14 and iT17 (manufactured by Flex Foam). In this study, demineralised water, $\mathrm{pH}=7.4$ PBS buffer solution and synthetic sweat with $\mathrm{pH}=4.3$ were also used. A MTS reagent (3-(4,5-dimethylthiazol-2-yl)-5-(3-carboxymethoxyphenyl)-2-(4-sulfophenyl)$2 \mathrm{H}$-tetrazolium, manufactured by Promega) and bovine serum were used in the biological tests for the analysis of cytotoxicity.

\section{Methods}

\section{Surface analysis of the tested materials}

Disk-shaped samples with a diameter between 8 and $10 \mathrm{~mm}$ were cut out of the tested materials. The disks were dried in a vacuum drier at a temperature of $80^{\circ} \mathrm{C}$ for 2 hours and were subsequently sprayed with gold until a layer of $5 \mathrm{~nm}$ was achieved. Subsequently, the samples were analysed using a Scanning Electron Microscope (SEM) manufactured by Phenom ProX. 10 Randomly selected locations of each samples were photographed at a magnification between 295 and 320 times.

\section{Hardness of the samples}

The authors decided to select hardness tests because it may guarantee representative results and may be applied along with the absorption and emissivity tests. 
The test was carried out using Shore durometers D and A type. The obtained hardness values were collected in Table no. 2.

\section{Determination of the tested materials' absorption of water and body fluids}

The samples of the tested materials (P1-P6) were placed in a vacuum drier and dried in a temperature of $80^{\circ} \mathrm{C}$ under a decreased pressure $(4.5 \mathrm{~mm} \mathrm{Hg})$ for 2 hours. After that time, the samples were weighed and transferred to separate phials. The phials were then divided into three groups. In the first group, each phial containing the tested material sample was filled with $10 \mathrm{ml}$ of deionised water; in the second group, $10 \mathrm{ml}$ of the $\mathrm{pH}=7.4$ PBS buffer solution was added, while in the third group, a solution imitating human sweat was added, namely the AATCC $\mathrm{pH}=4.3$ prepared according to instruction reported in the literature ${ }^{2}$. The phials with the samples were transferred for 8 hours to two separate laboratory incubators. The first was heated to the temperature of $21^{\circ} \mathrm{C}$ and the second one was heated to the temperature of $37^{\circ} \mathrm{C}$. After the lapse of that time, the samples were removed from the phials, dried using a paper towel and weighed. The absorption was calculated based on the following formula:

$X=\frac{m_{2}-m_{1}}{m_{1}} \cdot 100 \%$

where:

$\mathrm{m}_{1}$ - mass of the sample after drying,

$\mathrm{m}_{2}$ - mass of the sample after thermostating in the tested substance.

The 7-day cycle absorption test was conducted in the same way as it was for 8-hour test. But the samples were placed in laboratory incubators and heated to the temperatures of $21^{\circ} \mathrm{C}$ and $37^{\circ} \mathrm{C}$ for 7 days.

The samples of the tested materials (P1-P6) were placed in a vacuum drier, where they were dried in the temperature of $80^{\circ} \mathrm{C}$ under a decreased pressure of 4.5 $\mathrm{mmHg}$ for 2 hours. After that time, the samples were weighed and transferred to separate, open space. The phials were placed in a dark place in a ventilated room for a month (30 days). The mean at daily air room temperature was $21^{\circ} \mathrm{C}$ and a humidity of $65 \%$. After the lapse of that time, the samples were removed from the phials and weighed. The absorption was calculated based on the formula provided above (1).

\section{Determination of the water release, $\mathrm{pH}=7.4 \mathrm{PBS}$ buffer solution and $\mathrm{pH}=4.3$ sweat from the samples.}

For this test the release was measured after 8 hours of samples incubation in the solutions with water, $\mathrm{pH}=7.4$ PBS buffer solution and $\mathrm{pH}=4.3$ sweat at the temperatures of $21^{\circ} \mathrm{C}$ and $37^{\circ} \mathrm{C}$. The samples were prepared as it was provided in section 2.2.3. After 8 hours, they were removed from the solutions, the surface were dried with absorbent paper, the samples were weighed and placed on a dry absorbent paper in a shaded location at room temperature $\left(21^{\circ} \mathrm{C}\right)$. Each sample was weighed every 15 minutes until the mass of the sample returned to its initial value.

\section{Cytotoxicity - MTS assay}

MTS assay is a colorimetric method for cells viability and proliferation estimation in cytotoxicity assays. In MTS assay, a mitochondrial activity of living cells is proportional to their viability and number of survived cells. Metabolic activities of untreated cells (control population) is presented as $100 \%$ of viability, and treated cells should be compared to them. The toxicity of tested compounds is characterised as none or neutral if absorbance in MTS assay is comparable to the control (viability is the same or similar), whereas decreased absorbance indicates cytotoxicity and antiproliferative action (decreased or inhibited viability).Neonatal human dermal fibroblasts (NHDF-Neo; CC-2509, Lonza) were cultivated in a monolayer culture in DMEM-F12 (PAA, UK) supplemented with $10 \%$ of fetal bovine serum (Eurx, Poland) with the addition of $1 \%$ Antibiotic Antimycotic Solution (Sigma), under standard conditions $\left(37^{\circ} \mathrm{C}, 5 \% \mathrm{CO}_{2}\right)$. For the experiments, the cells were seeded on plates (Falcon) at a concentration of 200000 cells in fresh, $2 \mathrm{ml}$ of DMEM-F12 medium, for $96 \mathrm{~h}$ of incubation.Fragments of synthetic polymers, prepared as ultra-thin monolayer foil, in diameter of $5 \mathrm{~mm}$, were placed on sterile plates $(\varnothing 35 \mathrm{~mm}$, Falcon) and were sterilized with UV light for $20 \mathrm{~min}$ from both sides. After the sterilization, the materials were seeded with NHDF cells in concentration of 200000 cells in fresh $2 \mathrm{ml}$ of DMEM-F12 medium supplemented with $10 \%$ FBS (Sigma). After $96 \mathrm{~h}$ of incubation under standard and sterile conditions for all tested materials, an MTS assay was performed. The cells grown on the materials were washed with a PBS solution. According to the producer procedure, $20 \mu \mathrm{l}$ of yellowish MTS solution (Promega), in $100 \mu \mathrm{l}$ of PBS (PAA) were added to each plate. The plates were incubated for $2 \mathrm{~h}$ until the colour in the control wells was changed from light yellow to brown. The absorbance for formazan produced solely by alive cells was measured at a wavelength of $\lambda=490 \mathrm{~nm}$, using a microplate spectrophotometer (Epoch; BioTek).

The viability values were expressed as a percentage change in absorbance of the tested cells, relative to the control cells [\%].

viability $=\frac{A_{\text {sample }}}{A_{\text {control }}} \cdot 100 \%$

where:

$\mathrm{A}_{\text {sample }}$ - absorbance of the tested sample,

$\mathrm{A}_{\text {control }}$ - mean absorbance of the control.

\section{RESULTS}

To obtain some structured information about the porosity, the sample surface was tested. The presence of pores is directly responsible for the capability of materials to absorb water and body fluids. It can give a significant factor value in designing a material to be in continuous contact with the human body. The density of pores at the surface was assessed using SEM and their diameter was measured (Table no. 2). Below, selected SEM photographs have been presented, two per each of the tested samples. All samples were photographed at a magnification between 295 and 320 times. 
Table 1. SEM pictures of the tested structural materials

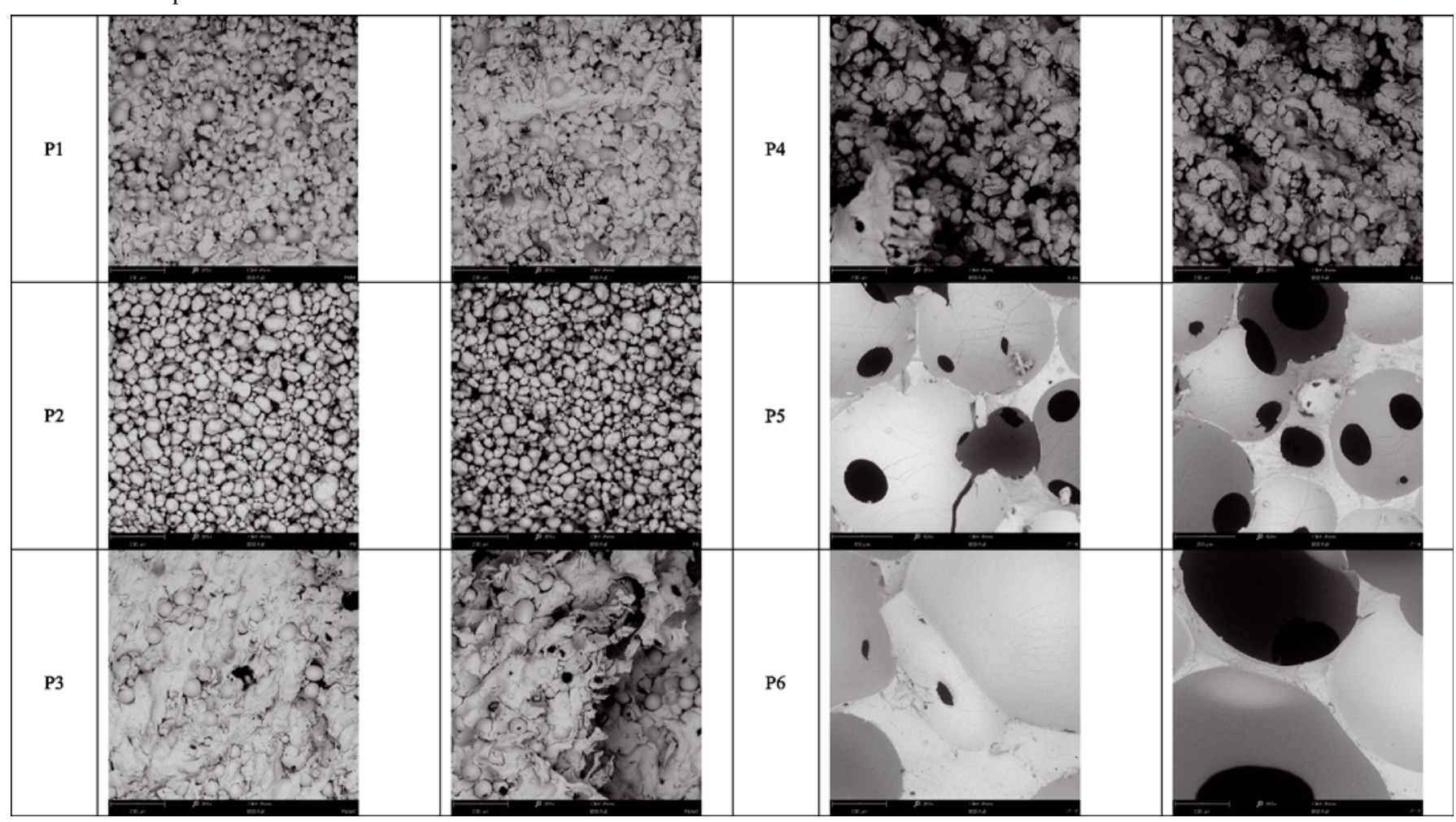

Assessment of the hardness of the samples

Table 2. The hardness of the tested samples (P1-P6) in the Shore D scale (samples P1-P4), (samples P5-P6) Shore A scale

\begin{tabular}{|c|c|c|c|c|c|c|c|c|c|c|c|c|}
\hline \multirow[b]{2}{*}{ Sample } & \multicolumn{10}{|c|}{ Measurement } & \multirow[b]{2}{*}{ Mean } & \multirow[b]{2}{*}{ Standard deviation } \\
\hline & 1 & 2 & 3 & 4 & 5 & 6 & 7 & 8 & 9 & 10 & & \\
\hline $\mathrm{P} 1$ & 75 & 75 & 72 & 72 & 72 & 75 & 71 & 73 & 75 & 72 & 73.2 & 1.62 \\
\hline $\mathrm{P} 2$ & 67 & 67 & 62 & 66 & 68 & 66 & 63 & 67 & 66 & 67 & 65.9 & 1.91 \\
\hline P3 & 71 & 63 & 67 & 69 & 65 & 67 & 71 & 68 & 69 & 64 & 67.4 & 2.76 \\
\hline P4 & 45 & 50 & 48 & 46 & 50 & 50 & 45 & 51 & 47 & 52 & 48.4 & 2.55 \\
\hline P5 & 7.5 & 8 & 8 & 8 & 8 & 6 & 8 & 8 & 6 & 8 & 7.22 & 0.64 \\
\hline P6 & 36 & 36 & 36 & 37 & 36 & 34 & 36 & 36 & 35 & 37 & 35.9 & 0.88 \\
\hline
\end{tabular}

Absorption assessment of the samples (demineralised water with $\mathrm{pH}=5.5$, $\mathrm{PBS}$ with $\mathrm{pH}=7.4$, sweat with $\mathrm{pH}=4.3$, air moisture)

Due to the attempt to use hydrophilic plastics processed using additive production methods in the construction of various types of mechatronic devices' components, a study was initiated on the absorption and emissivity of the most fundamental fluids that the devices are to work with. As the scientific literature provides, plastics may be affected by fluids to a various extent, causing more or less adverse effects such as increase of the mass of the material or changes in the geometric dimensions caused by swelling due to the absorption. Moreover, the phenomenon of extraction, that is, the separation of components that are soluble in fluids may occur, as well as other properties of the material may change. For that reason, absorption and emissivity tests of selected plastic materials were conducted based on the provisions of the standard entitled (3). The result of these tests allowed to determine the applicability of these materials, that is, their usability in an implemented project.

To determine the hydrophilic properties of the analysed materials, a series of tests was conducted on samples prepared based on the materials. The tests consisted in saturation of the samples' structures with selected liquids and subsequently removing them. The material samples in the form of $5 \times 5 \times 5 \mathrm{~mm}$ cubes were produced for that purpose by means of additive technology using plastic powder sintering technique. Subsequently, the samples were dried in a laboratory drier in a temperature of $80^{\circ} \mathrm{C}$ while measuring the mass of the materials from time to time until no further changes in mass were observed and the samples were considered fully dry (free of volatile agents, especially water). This way, the so-called conditioning process was conducted in line with professional literature.

The saturation experiment was commenced with submerging the samples in a vessel with deionised water with a acidity of $\mathrm{pH} 5.5$. The test was conducted at the air humidity of $65 \%$ and a temperature of $37^{\circ} \mathrm{C}$ (due to the temperature of human body, to which the material is dedicated), by means of a discrete measurement of the mass of the samples in 15 minutes intervals, until the assumed time limit of 8 hours has passed (due to the mean daily time of physical work). The assumed time resulted from the target nominal time of exposure of the material to the fluid agent. Analogous tests were conducted using the PBS buffer solution with $\mathrm{pH}$ of 7.4 as well as the so-called "artificial sweat" with the $\mathrm{pH}$ of 4.3. The results obtained in the tests have been presented in Figure 1. 


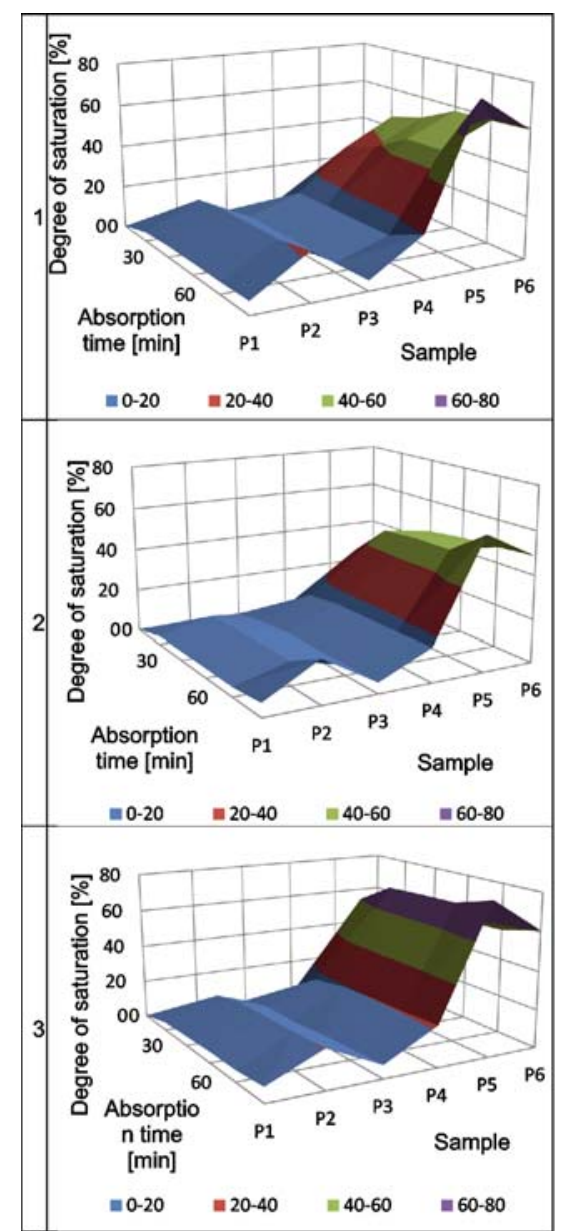

Figure 1. Saturation characteristics of material samples with selected substances with the acidities of 1) $\mathrm{pH}=5.5$; 2) $\mathrm{pH}=7.4 ; 3) \mathrm{pH}=4.3$ against time at the fluid temperature of $37^{\circ} \mathrm{C}$
The conducted study showed that samples submerged in synthetic sweat, the $\mathrm{pH}$ of which is 4.3 , indicated the shortest time and the highest absorption values. The samples absorbing the basic PBS $=7.4$ solution act in a very different manner, as the full saturation occurs much later (Fig. 2).

While assessing the absorption capacity of each type of materials, one may note that samples marked as P5 and P6 are influenced by the action of the referred to above fluids to the highest extent. The samples marked as P3 and P4 absorb the substances much slower and to a lesser extent. The absorption was even slower and smaller amounts of fluid were absorbed in case of samples marked P1 and P3. Solutions with the $\mathrm{pH}$ values of 5.5 and 7.4 - basic, cause a certain lack of predictability in the process of absorption of the analysed materials. The basic solution acting on the material marked as $\mathrm{P} 4$ causes a decrease in the absorption capacity and the storage capacity of that sample. Subsequently, an emissivity test was conducted for the saturated samples. The test was conducted identical to that of the absorption test, until the moment in which the samples were fully dry. The results of the conducted tests have been presented in Figures 3,5 and 6 .

\section{Conclusions regarding emissivity}

Due to the lowest absorption, as compared to the remaining samples, it may be concluded that the samples exposed to a basic solution dry much faster. Also the acidic solution with a $\mathrm{pH}$ of 4.3 had a positive impact on the drying of samples. The process of drying was the slowest in case of the neutral solution. Similarly to the above, tests were also conducted at nominal room

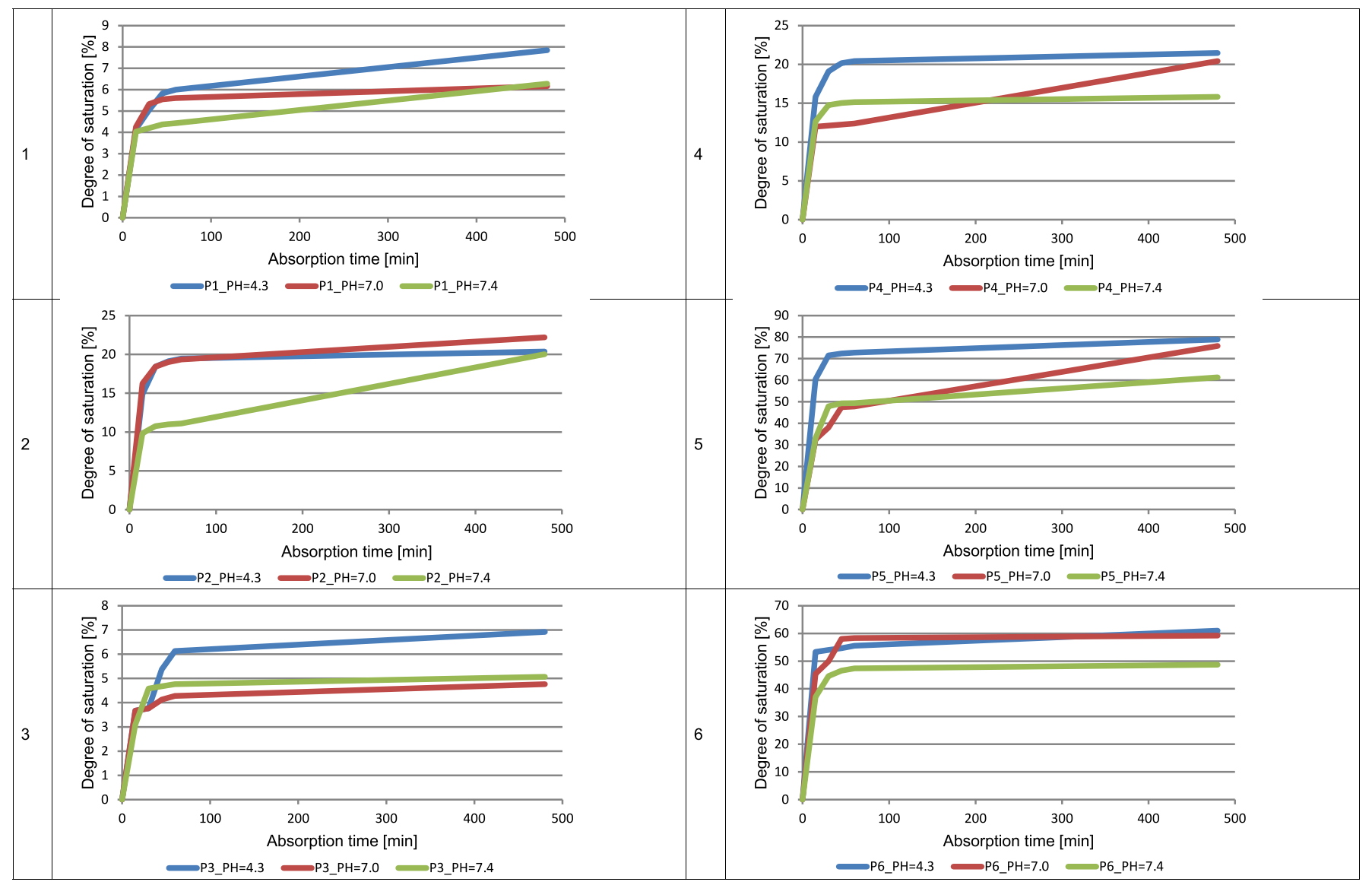

Figure 2. Comprehensive characteristics of the analysed material samples against the time of absorption of selected solutions with acidity of body fluids at a temperature of $37^{\circ} \mathrm{C}$ 


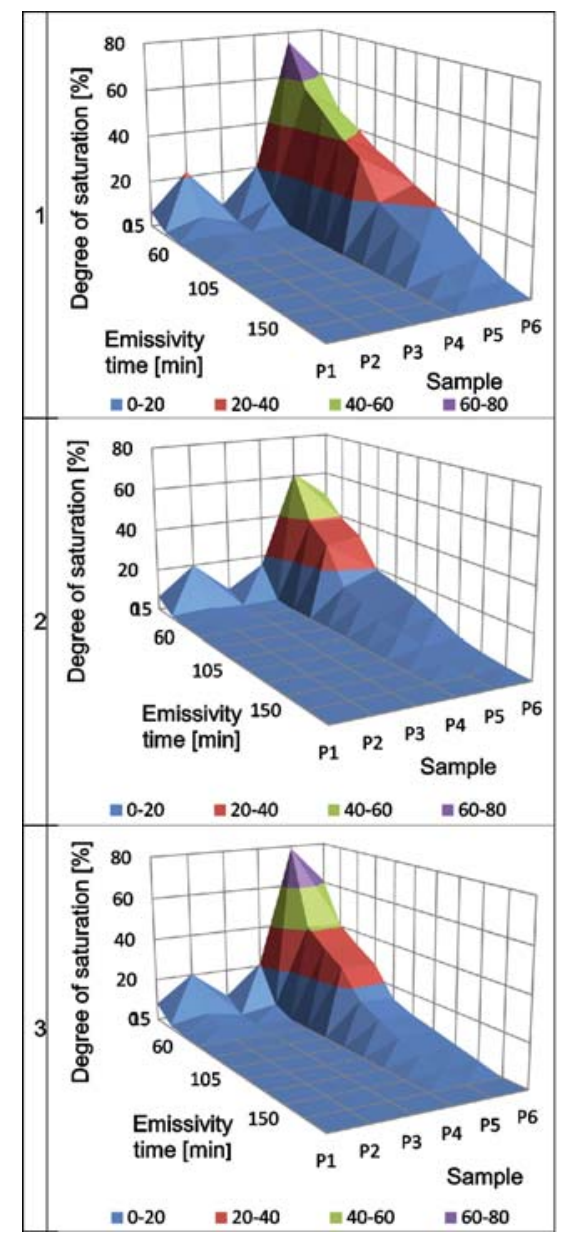

Figure 3. Release characteristics of substances from the material samples, with $\mathrm{pH}$ values of: 1) $\mathrm{pH}=5.5 ; 2$ ) $\mathrm{pH}=7.4$; 3) $\mathrm{pH}=4.3$, respectively, against time, in temp. of $37^{\circ} \mathrm{C}$ temperature (and liquid temperatures) of $21^{\circ} \mathrm{C}$ at air humidity of $65 \%$. The experiment was commenced with absorption tests, which allowed to obtain the values of saturation growth of the materials with various liquids as a percentage. The saturations level were observed in fixed intervals of 15 minutes for one hour as well as after 8 hours.

Based on the obtained results of the experiments, it can be deserved that the highest absorption was exhibited by materials absorbing the acidic solution (the so-called synthetic sweat) with a $\mathrm{pH}$ value of 4.3 or the basic solution with the $\mathrm{pH}$ of 5.5. The lowest absorption was exhibited by the samples exposed to the buffer solution with a $\mathrm{pH}$ of 7.4 .

\section{Emissivity}

The results of the tests conducted in the temperatures of $21^{\circ} \mathrm{C}$ and $37^{\circ} \mathrm{C}$ exhibited similarities under the influence of the solutions they were exposed to. The general differences in the achieved results concern the time of emissivity of fluids, which occurred as shorter in case of higher ambient temperature. The samples absorbing the acidic solution were saturated very quickly. The time required to achieve the full saturation of the samples was much longer than the time required for the samples to become fully dry (Fig. 4, 7 and 8). Materials marked P2, P4 and especially the P5 and P6 samples are characterized by high absorption capacity, or rather a high tendency to buffer the absorbed fluid. As a result, when designing and producing components based on these materials, one should be aware of the possibility of a significant, usually adverse increase of their mass.

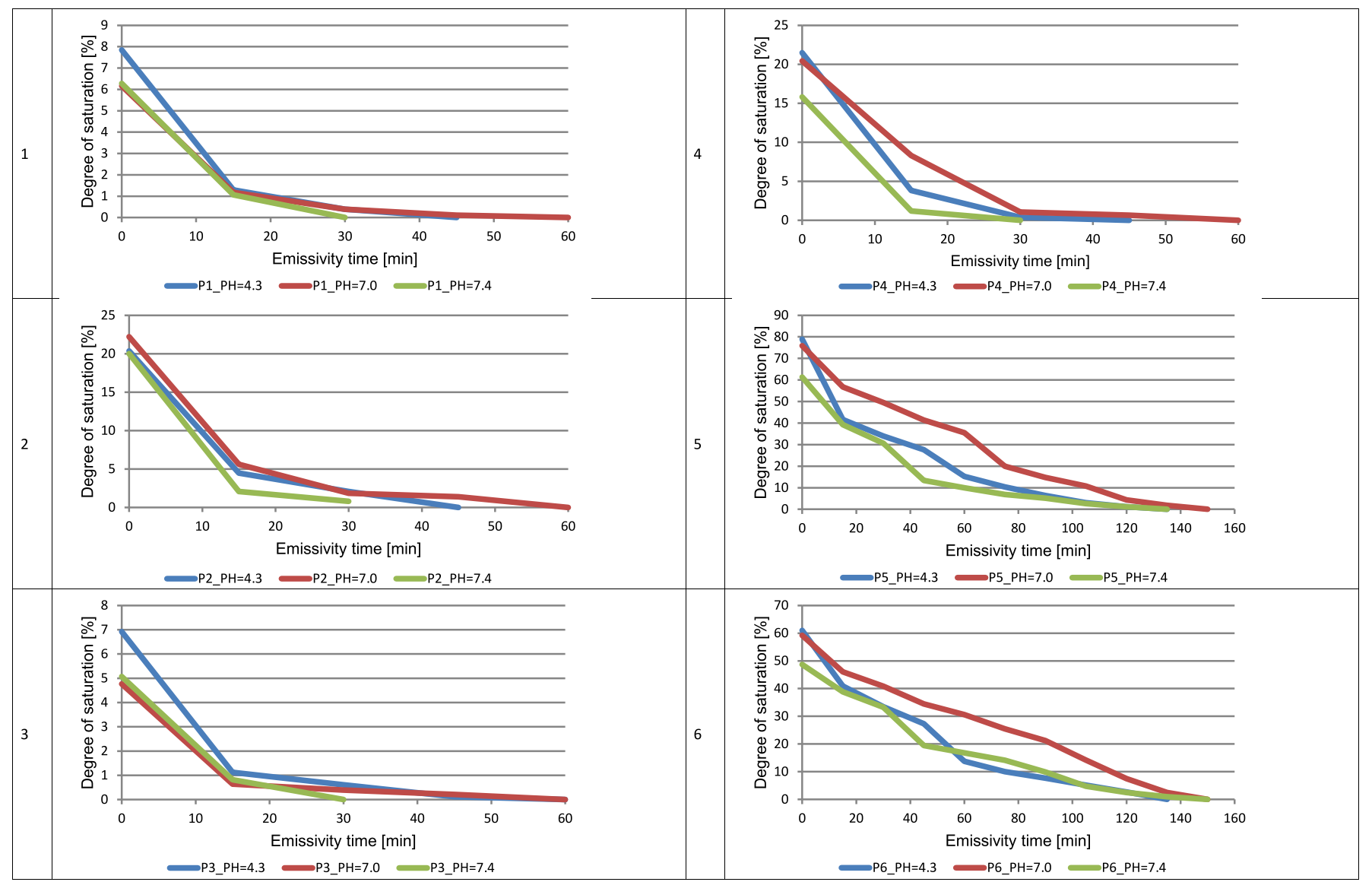

Figure 4. Comprehensive characteristics of the analysed material samples against the time of emissivity of selected solutions with acidity of body fluids at a temperature of $37^{\circ} \mathrm{C}$ 


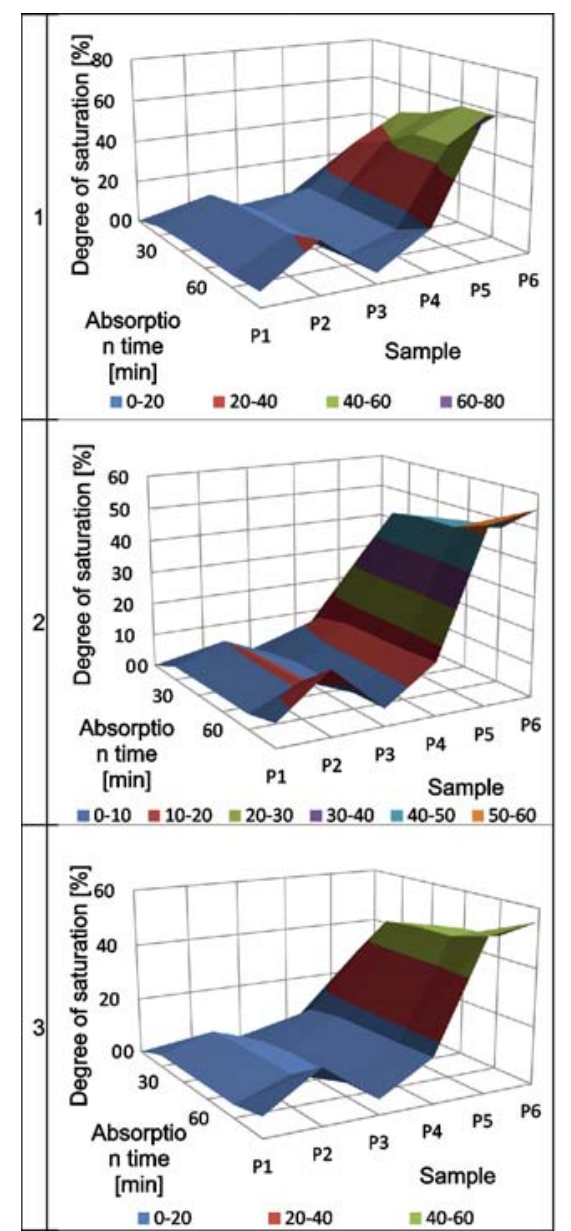

Figure 5. Saturation characteristics with selected fluids: with the acidities of 1) $\mathrm{pH}=5.5$;2) $\mathrm{pH}=7.4$; 3) $\mathrm{pH}=4.3$ at the temperature of $21^{\circ} \mathrm{C}$

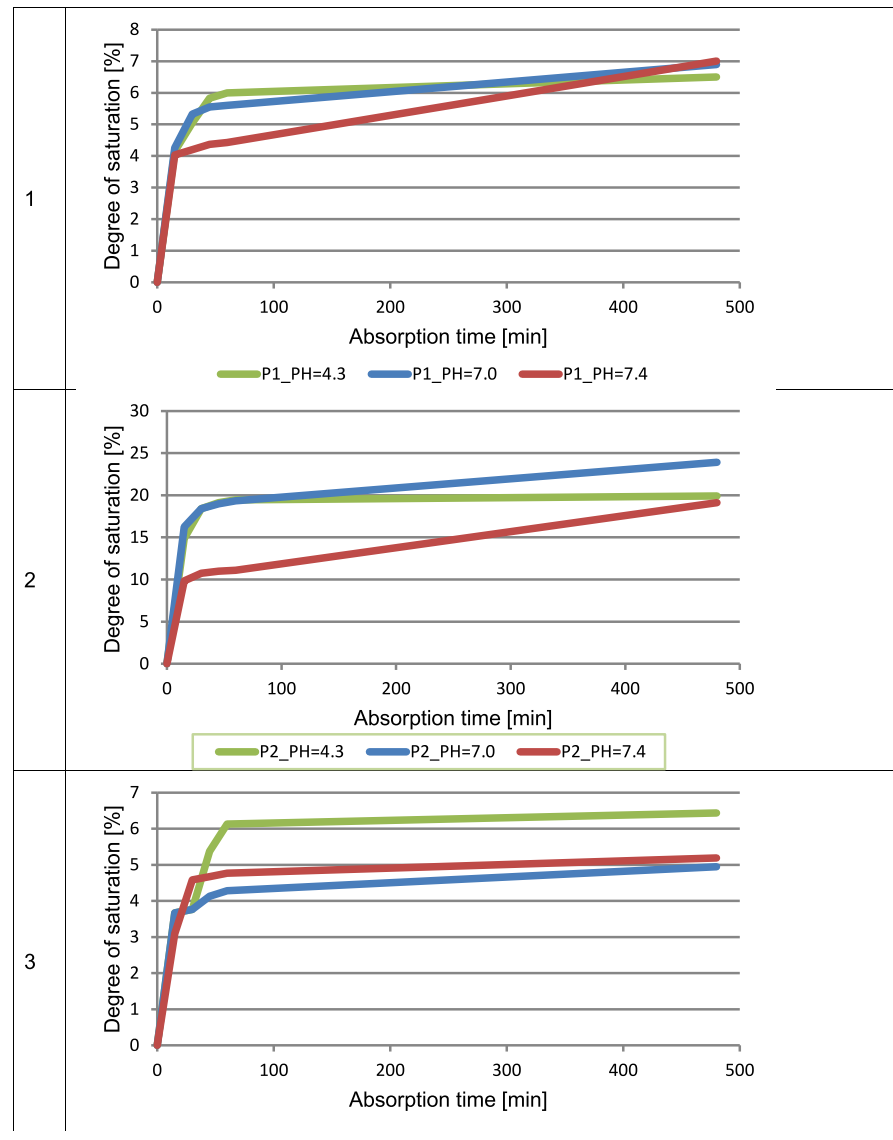

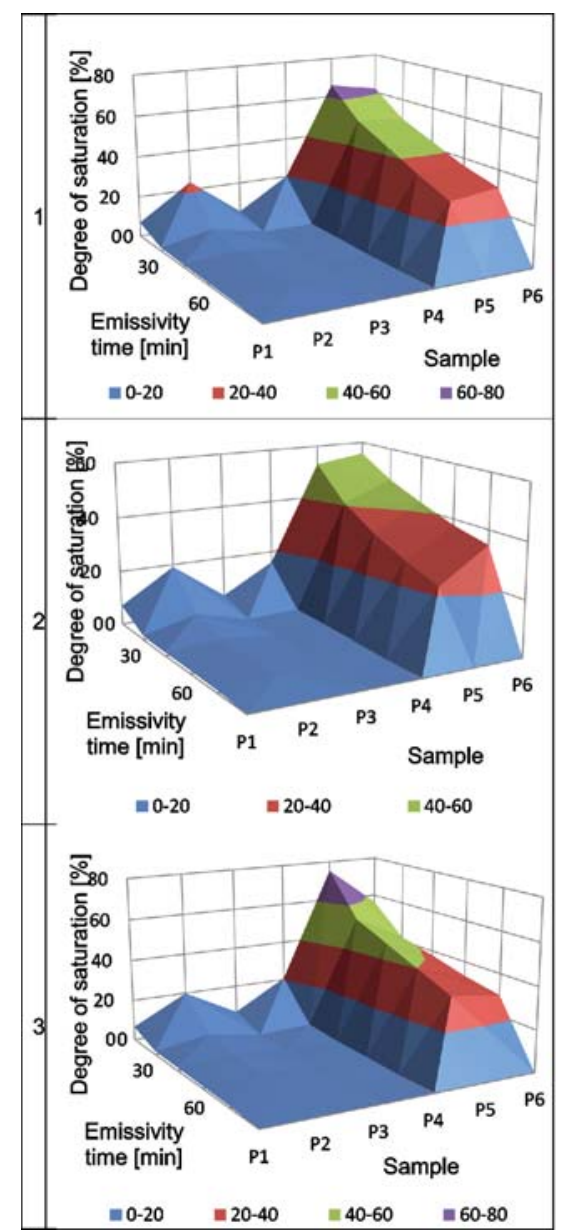

Figure 7. Release characteristics of substances from the material samples, with $\mathrm{pH}$ values of: 1 ) $\mathrm{pH}=5.5 ; 2$ ) $\mathrm{pH}=7.4 ; 3) \mathrm{pH}=4.3$, respectively, against time, in temp. of $21^{\circ} \mathrm{C}$

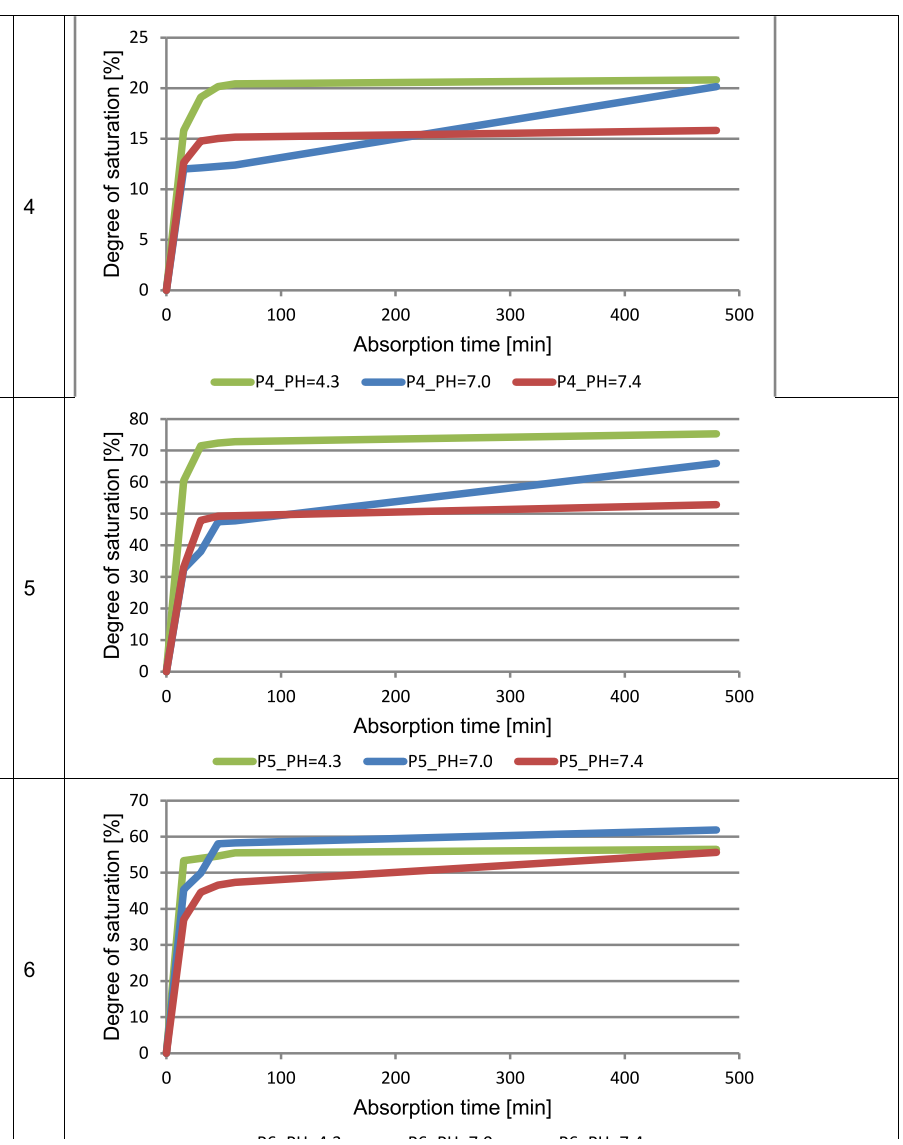

Figure 6. Comprehensive characteristics of the analysed material samples against the time of absorption of selected solutions with acidity of body fluids at a temperature of $21^{\circ} \mathrm{C}$ 


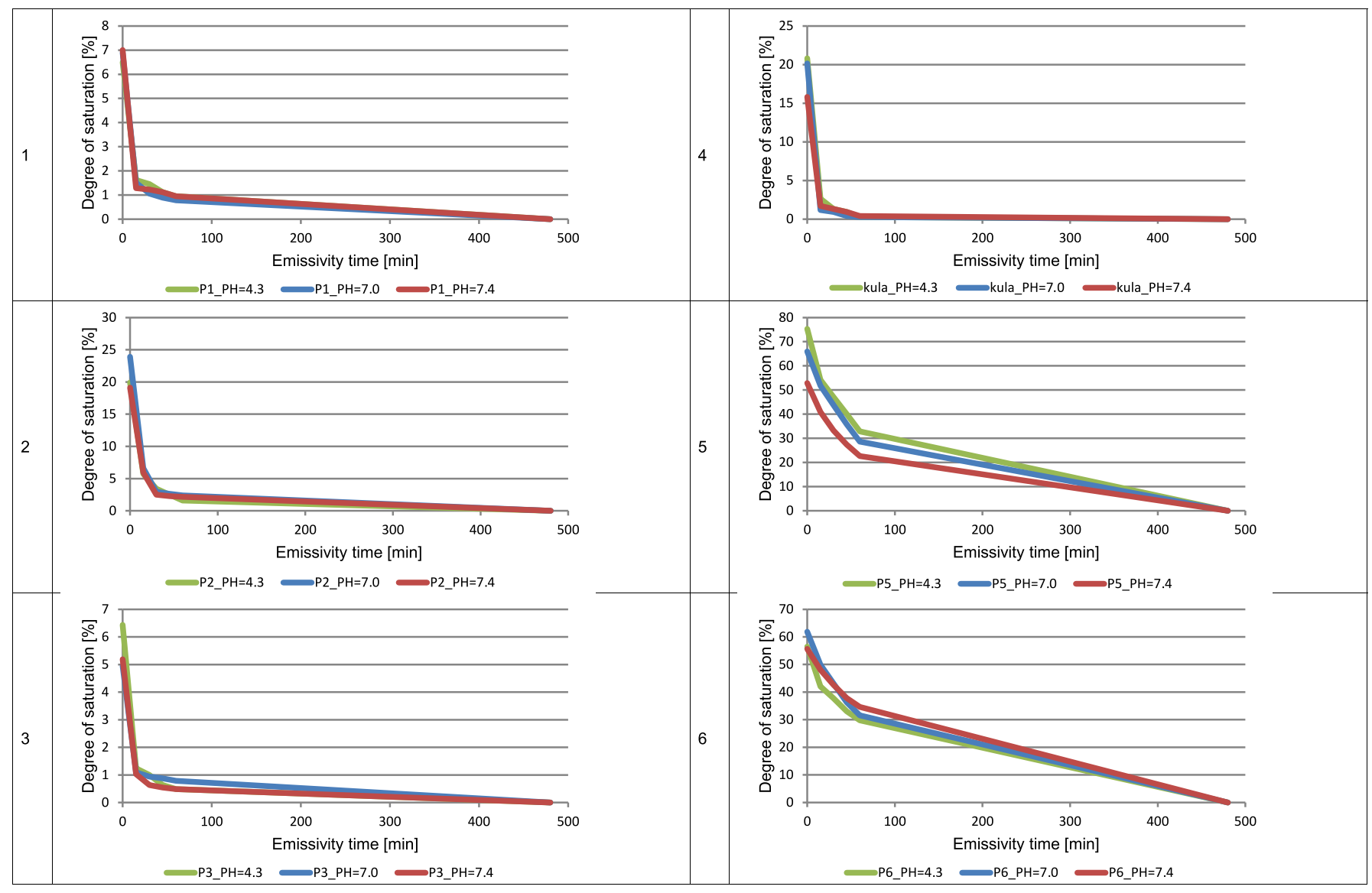

Figure 8. Comprehensive characteristics of the analysed material samples against the time of emissivity of selected solutions with acidity of body fluids at a temperature of $21^{\circ} \mathrm{C}$

\section{Cytotoxicity assay}

The aim of the study was to estimate the toxicity of the tested compounds against normal human fibroblasts, followed by a $96 \mathrm{~h}$ MTS assay. The tested materials were classified as potential bio-composites for long-term interactions with human skin. Cytotoxicity was defined as a material's feature/ability to reduce viability after time-dependent contact of model NHDF cell line, in comparison to the untreated control. All cellular disturbances were observed as mitochondrial enzymes activity reduction in MTS assay, which resulted in final viability reduction or cellular death. Results were calculated after the absorbance measurements and presented as relative viability to the controls (\% of the control).

The obtained results suggested that the tested materials did not display toxic effects against a normal NHDF cell line (Fig. 9). Incubation with P1. and P5, after $96 \mathrm{~h}$ of incubation stimulated cellular viability in

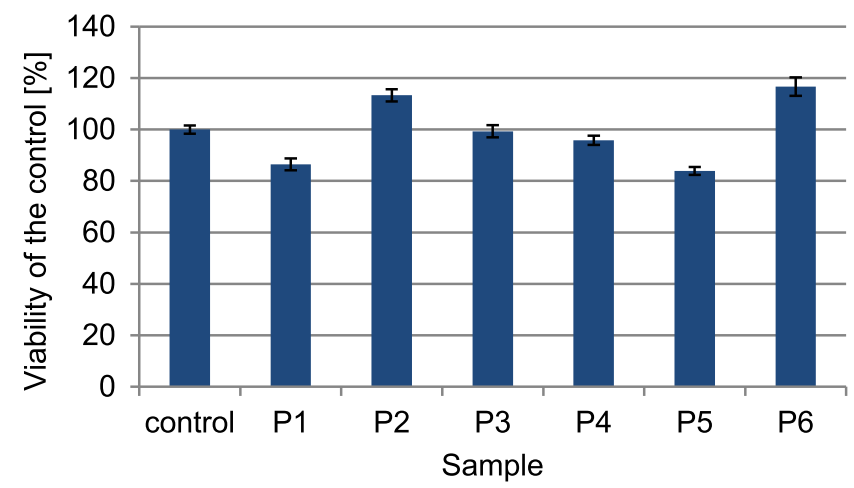

Figure 9. Cytotoxicity of tested materials after $96 \mathrm{~h}$ of incubation
$15 \%$ above the control's level. Probably, after $96 \mathrm{~h}$ of incubation, the fibroblasts could use the carbon from the materials as nutritional supplementation, which could also stimulate cells proliferation. Materials P3 and P4 were rather neutral to the cells - the viability was comparable to the control. Only materials P2 and P6 had an impact on the NHDF cells as anti-proliferative agents, because they reduced the cell viability by about $15 \%$ as compared to the control. The viability reduction could be also caused by other, unspecific reasons. The most probable one being the long time of incubation, where during $96 \mathrm{~h}$ cells could start to die. During such a long time, cells start to die in natural process, which is a result of nutrition expiration in the medium. However, $85 \%$ of cells survival in comparison to the control is still optimistic and does not eliminate these materials from the next stages of tests.

\section{CONCLUSIONS}

Based on the obtained results it was observed that the absorption capacity of all the tested fluids decreases along with the increase in the hardness of the material. Polyamide 12-based composites are characterized by a higher hardness (Shore's D scale) than polyurethanes (Shore's A scale), which results in a smaller absorption both of demineralised water as well as of the PBS buffer solution and synthetic sweat. The common feature of all the tested plastics is the fact that both the pace of absorption capacity and emissivity are the fastest in the first 15 minutes of the experiment. Moreover, all tested exhibited no cytotoxicity to normal human cells. So it allows to use these materials as safe with the contact 
human body. The tested materials may be processed using additive technologies, which allows to produce personalized products for a given recipient.

\section{ACKNOWLEDGEMENT}

This publication was financed from the measures granted by The National Centre for Research and Development for the project POIR.01.01.01-00-0537/16-00.

\section{LITERATURE CITED}

1. Ward, I.M. (1975) Mechanical properties of polymers as engineering plastics. Warsaw: PWN. (in Polish).

2. Callewaert, Ch., Buysscheart, B., Vossen, E. Fievez, V., Van de Wiele, T. \& Boon, N.; Artificial sweat composition to grow and sustain a mixed human axillary microbiome; J. Microbiol. Methods 103 (2014) 6-8.

3. Plastics - Determination of Water Absorption (ISO 62:1999).

4. Błażewicz, S. \& Marciniak, J. (2016) Biomateriały Tom 4. Akademicka Of. Wydaw. Exit.

5. Martin, R. (2008) Ageing of composites. CRC Press. Cambridge England.

6. Curtis, R.V. \& Watson, T.F. Dental biomaterials Imaging, testing and modelling. CRC Press. Cambridge England.

7. Pusz, A., Szymiczek, M. \& Michalik, K.; Ageing process influence on mechanical properties of polyamide-glass composites applied in dentistry; J. Achiev. Mater. Manufact. Engineer. 38 (2010) 49-55.

8. Rojek, M., Szymiczek, M. \& Wróbel, G.; Mechanical properties of polyamide matrix composites filled with titanates modified-coal; J. Achiev. Mater. Manufact. Engineer. 46 (2011) 25-32.

9. Pusz, A., Szymiczek, M. \& Michalak, K.; Topography and the structure of the surface of polyamide-glass composites after the ageing process; J. Achiev. Mater. Manufact. Engineer. 44 (2011) 42-49.

10. Macura-Karbownik, A., Chladek, G., Żmudzki, J. \& Kasperski, J.; Chewing efficiency and occlusal forces in PMMA, acetal and polyamide removable partial denture wearers; Acta Bioengine. Biomech. 18 (2016) 127-134.

11. Mielańczyk, A., Skonieczna, M., Mielańczyk, Ł. \& Neugebauer, D.; In Vitro Evaluation of Doxorubicin Conjugates Based on Sugar Core Nonlinear Polymethacrylates toward Anticancer Drug Delivery; Bioconjugate Chem. 27 (2016) 893-904. 